\title{
Local inpatient units may increase patients' utilization of outpatient services: a comparative cohort-study in Nordland County, Norway
}

This article was published in the following Dove Press journal:

Psychology Research and Behavior Management

28 October 2015

Number of times this article has been viewed

Lars Henrik Myklebust ${ }^{1}$

Knut Sørgaard ${ }^{1,2}$

Rolf Wynn ${ }^{2}$

'Psychiatric Research Centre of North Norway, Nordland Hospital

Trust, Bodø, ${ }^{2}$ Department of Clinical Medicine, Faculty of Health Sciences, UiT The Arctic University of Norway, Tromsø, Norway
Correspondence: Rolf Wynn

Department of Clinical Medicine, Faculty of Health Sciences, UiT The Arctic University of Norway, N-9037 Tromsø, Norway

Email rolf.wynn@gmail.com
Objectives: In the last few decades, there has been a restructuring of the psychiatric services in many countries. The complexity of these systems may represent a challenge to patients that suffer from serious psychiatric disorders. We examined whether local integration of inpatient and outpatient services in contrast to centralized institutions strengthened continuity of care.

Methods: Two different service-systems were compared. Service-utilization over a 4-year period for 690 inpatients was extracted from the patient registries. The results were controlled for demographic variables, model of service-system, central inpatient admission or local inpatient admission, diagnoses, and duration of inpatient stays.

Results: The majority of inpatients in the area with local integration of inpatient and outpatient services used both types of care. In the area that did not have beds locally, many patients that had been hospitalized did not receive outpatient follow-up. Predictors of inpatients' use of outpatient psychiatric care were: Model of service-system (centralized vs decentralized), a diagnosis of affective disorder, central inpatient admission only, and duration of inpatient stays.

Conclusion: Psychiatric centers with local inpatient units may positively affect continuity of care for patients with severe psychiatric disorders, probably because of a high functional integration of inpatient and outpatient care.

Keywords: psychiatry, hospitalization, decentralization, outpatients, continuity of care, health service research, affective

\section{Introduction}

The deinstitutionalization of mental health care in many countries has resulted in complex systems of services that may represent a challenge to patients suffering from serious psychiatric disorders. ${ }^{1,2}$ The essence has been a downsizing of central psychiatric institutions in favor of community-based services with emphasis on outpatient treatment and case-management of the various services. "Continuity of care" has long been a key concept and a "strategic priority" in the evaluation of mental health services. ${ }^{4,5}$ It is used in a variety of ways, as a measure of outcome and processes as well as a benchmark of quality of care. ${ }^{6,7}$ It represents the availability of a full range of mental health services tailored to the needs of people, especially individuals suffering from serious psychiatric disorders. ${ }^{8,9}$ Studies suggest it is related to important health outcomes such as higher quality of life, improved community functioning, reduced severity of symptoms, and increased service satisfaction. ${ }^{10-16}$ Recent research has focused on whether the same clinicians should care for patients across inpatient and outpatient settings or whether the care should be offered by separate more specialized teams, referred to by Omer et al as "continuity systems" and "specialized 
systems", respectively. ${ }^{17}$ Some studies have suggested that continuity systems are associated with a reduced number of hospitalizations, but two of our former studies question this and find that continuity systems are associated with more use of both inpatient and outpatient services. ${ }^{17-19}$ Findings in this area of research have been inconsistent, and current reforms of psychiatric services in Europe are taking place based on limited scientific evidence. ${ }^{17}$

The present Norwegian psychiatric system is characterized by an extensive decentralization of both outpatient and inpatient services. General psychiatric services in welldefined geographic sectors are typically organized at a local District Psychiatric Centre (DPC), whereas highly specialized units for eating disorders, serious depression and psychosis, and involuntary treatment are located at a Central Mental Hospital $(\mathrm{CMH}){ }^{20,21}$ The main drive behind this restructuring was the need to provide high-quality psychiatric care in local communities. Continuity through the whole chain of services from primary care to hospital treatment was also a central concern. This decentralization also has an ideological underpinning, with a belief in the importance of local solutions to various social issues. ${ }^{18-21}$

The central guidelines for the Norwegian DPCs emphasize the adjustment of services to meet local needs. ${ }^{20}$ The structure of the DPCs is still in development, and different types of models therefore coexist. Some depend more on the inpatient services of the $\mathrm{CMH}$, while other DPCs rely on psychiatric beds in local units and might be considered as small local psychiatric hospitals. Although such local inpatient units could be advantageous, the literature focusing on them is limited. ${ }^{17,22}$ We have previously described some differences between service-systems with and without beds available locally. We have addressed the issue of how different service-systems may be associated with varying use of coercion, ${ }^{23,24}$ including rates of involuntary admission..$^{25,26}$ Furthermore, we have examined how different servicesystems are associated with rates of emergency admissions and continuity of care. ${ }^{18,19}$ In the present study, we seek to further expand knowledge about the latter topic by studying more data from a longer observation period (a 4-year patient sample) to examine whether having beds available locally also affects the use of outpatient services, ie, an aspect of continuity of care for individual patients.

\section{Methods \\ Design}

The present study is a comparative, retrospective cohort study of the total psychiatric services in two areas in North Norway, based on a prevalence sample from the routine case-registries of two DPCs and the CMH over the years 2003-2006. The records from all the services were linked by the patients' eleven-digit personal identity numbers. Missing data were collected from medical records of individual patients.

\section{Study areas}

Two neighboring DPCs in the Nordland County, North Norway, are particularly interesting because they are organized quite differently, but have similar catchment area characteristics regarding social conditions, subsistence, and demographic structures. ${ }^{18}$ Both areas have a comparable infrastructure, with two cities, two larger harbors, and two airports each, ${ }^{27}$ located approximately $25-30$ minutes flight from the city of Bodø and the $\mathrm{CMH} .{ }^{28}$ The area of Vesterålen has somewhat more inhabitants $(30,465)$ than Lofoten $(22,469)$. In Vesterålen, $59.7 \%$ of the population are aged between 18 years and 65 years, while this is the case for $56.7 \%$ in Lofoten. Of this population, $51.3 \%$ (Vesterålen) and $51.8 \%$ (Lofoten) are male. ${ }^{29}$ In both areas, $2 \%$ of the population receive disability pension on the basis of a psychiatric diagnosis. ${ }^{30}$

In Lofoten DPC, the emphasis is on outpatient services, with two outpatient clinics, two day-hospital units, and only six beds at the local general hospital staffed with regular nurses and doctors. Vesterålen DPC, on the other hand, provides local inpatient care at three local units, staffed with psychiatric nurses and psychiatrists, in addition to one outpatient clinic and a limited day-care unit. The main difference between the DPCs with relevance for this study lies in the location of psychiatric beds. At one of them (Vesterålen DPC), as much as $70 \%$ of the inpatient stays are at three local psychiatric units, while the remaining 30\% are at the $\mathrm{CMH}$ in the city of Bodø. At the other (Lofoten DPC), $90 \%$ of the inpatient stays are at the $\mathrm{CMH}$ and only $10 \%$ in the small local somatic hospital. ${ }^{18,19}$

The two systems may be termed a "local institution-based model" (ie, in Vesterålen) and a "centralized model" (ie, in Lofoten). ${ }^{18,19}$

\section{Analyses}

The total prevalence sample for the years of 2003-2006 included 2,719 individual patients aged between 18 and 65 years. From this, we extracted a subsample of 690 patients that had at least one inpatient stay during the observational period.

The available variables were sex, age, diagnoses, unit, and utilization of services (duration of inpatient stays, number of outpatient consultations, and days in day-hospital). 
The diagnoses were grouped into broad categories based on International Classification of Diseases, Revision 10 (ICD-10) criteria: substance abuse disorders (F10-19), psychotic disorders (F20-29), affective disorders (F30-39), and anxiety disorders (F40-49). Rare conditions were grouped under "others", in addition to "psychiatric observation".

We calculated the proportion of inpatients that also received outpatient care before or after hospitalization, and the extent of their service utilization over the observational period. In order to further disentangle the effect of bed-localization from other possible aspects of the two service-systems that might affect continuity of care, this sample was divided into patients with central hospitalization only versus patients with local inpatient treatment (and/or). Bivariate differences were tested by chi-square tests and Students $t$-tests.

In order to control for possible confounders and interaction effects, all variables were entered in a stepwise manner as predictors in a logistic regression model. The dependent variable was "Has been in outpatient care $(\mathrm{y} / \mathrm{n})$ ". Due to skewed distributions, the continuous variables were logtransformed before being entered into the model.

\section{Ethical standards}

The authors assert that all procedures contributing to this work comply with the ethical standards of the relevant national and institutional committees on human experimentation and with the Helsinki Declaration of 1975, as revised in 2008. The study was approved by all relevant agencies, including the Regional Medical Ethics Committee, the Norwegian Data Protection Agency, and the Norwegian Patient Register. Due to the nature of the study, the Regional Medical Ethics Committee decided that the study did not require the consent of individual patients.

\section{Results}

In the centralized model, $54.4 \%$ of the patients were males compared to $45.7 \%$ in the other model $(P<0.05)$. The difference in mean age was $41.2(\sigma=14.1)$ years vs $39.8(\sigma=13.8)$ years, not significant. For diagnoses, there were no significant differences in proportion of categories between the models. For the inpatients' pattern of outpatient utilization, the results are presented in Table 1.

A considerably larger proportion of the inpatients in the local institution-based model also utilized outpatient consultations, compared to what was the case in the centralized model (77.4\% vs $47.8 \%$ ). A phi coefficient of 0.326 $(P=0.001)$ indicates a medium effect-size of inpatient location. ${ }^{31} \mathrm{~A}$ difference was found also for outpatient utilization for these patients, where the mean number of outpatient consultations per patient was almost three times higher in the local institution-based model (14.0) than that in the other model (5.1).

Interestingly, these differences diminished for patients hospitalized at the CMH only (ie, they had not been hospitalized locally in addition to at the $\mathrm{CMH}$ ) when both models were compared. For these patients, there were no significant differences in the rates of outpatient care $(46.6 \%$ vs $45.3 \%$ ) nor in the mean number of outpatient consultations (6.3 vs 4.5$)$.

Concerning the possible confounding of service variables and patient variables for the differences in outpatient utilization, Table 2 shows the logistic regression model. All variables, including patient variables and treatment variables, were entered stepwise in the model. The total model containing all predictors was statistically significant $\left(\chi^{2}\right.$ $=140.131, d f=10, P<0.000$ ), with an overall goodness of fit $(-2 \mathrm{Log}$ likelihood) at $762.275(P<0.000)$. A sensitivity of $47.8 \%$ and a specificity of $85.0 \%$ indicated that it could distinguish between inpatients in outpatient care or not. The model explained between 18.4\% (Cox and Snell R-Square) and $25.2 \%$ (Nagelkerke R-Square) of the total variance.

The four covariates with a unique and statistically significant contribution were service model, the diagnosis of affective disorders, central inpatient admission only, and duration of inpatient stay. Service model emerged as the strongest predictor, indicating that an inpatient in the local institution-based model was more than three times more

Table I Utilization-patterns of outpatient services for inpatients in two different models of mental health care 4-year registered prevalence sample (2003-2006)

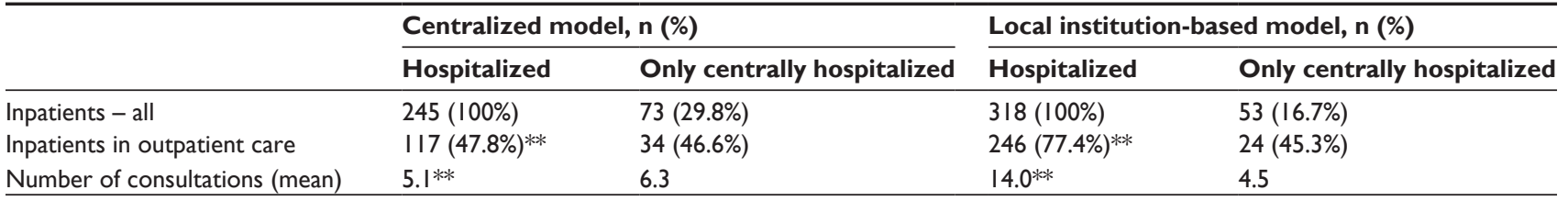

Note: $* * P<0.01$, when service models are compared. 
Table 2 Logistic regression model of inpatients' utilization of outpatient care

\begin{tabular}{lllll}
\hline Variable & B & Sig & Exp (B) & 95\% Cl \\
\hline Sex & -0.226 & 0.222 & 0.798 & $0.555-1.147$ \\
Age (years) & -0.009 & 0.148 & $0.99 I$ & $0.978-1.003$ \\
Affective disorders & 0.976 & 0.003 & 2.653 & $1.404-5.012$ \\
Duration of inpatient stay & 0.267 & $0.03 \mathrm{I}$ & 1.305 & $\mathrm{I} .025-1.662$ \\
Service-model & $\mathrm{I} .405$ & 0.000 & $4.05 \mathrm{I}$ & $2.2759-6.020$ \\
Central admission only & -0.897 & 0.000 & 0.408 & $0.26 \mathrm{I}-0.638$ \\
Constant & 0.479 & 0.203 & 1.615 & \\
\hline
\end{tabular}

Abbreviations: $\mathrm{Cl}$, confidence interval; Sig, significance.

likely to also use outpatient care, compared to the patients in the centralized model. Further, inpatients from either catchment area admitted to the CMH only, were less likely to utilize local outpatient services. The second strongest predictor for utilization of outpatient care was the diagnostic category of affective disorders. Also, longer inpatient stays increased the likelihood of also receiving outpatient consultations.

\section{Discussion}

In our retrospective cohort study based on the routine caseregistries of two models of local mental health services during a 4-year period, the main findings suggest that inpatients in a local institution-based model of services utilize more of both inpatient and outpatient resources, and are more often in continued care compared to a more centralized model with more separated in- and outpatient units. This is in line with our prior findings,,${ }^{19}$ and lends support to a recent review on the topic that suggested that continuity of care may be beneficial for inpatients, but not that it reduces hospitalization rates or utilization of care. ${ }^{17}$

Of a total of 690 inpatients included in the study, a majority of inpatients in the local institution-based model also utilized outpatient consultations. However, this was not the case in the centralized model, where a substantial proportion of inpatients did not receive outpatient care. This difference seems to be dependent on the degree of functional integration of inpatient and outpatient services. Patients from either system hospitalized at the $\mathrm{CMH}$ only were equally less inclined to use the local outpatient services. Demographic and clinical variables such as sex, age, and diagnosis did not alter these effects. In addition, inpatients with affective disorders (depression) utilized outpatient care more than patients in other diagnostic groups.

There may be several explanations to these results. We found the distinction between "continuity systems" and "specialization systems" very useful. ${ }^{17}$ Continuity is by this definition often provided by the same therapist in inpatient and outpatient settings, in contrast to specialized separate teams responsible for different treatment modes. Our results may depend on similar differences in organization between our two models of services. In the local institution-based model, the management and clinicians may handle the transitional phase from inpatient to outpatient status more effectively than specialized teams (ie, in our centralized model). Patients in the centralized model may not be as readily followed up locally after discharge from the central hospital because of the considerable geographical distance between the inpatient units and the outpatient clinic. In contrast, this may be easier in several ways if patients are discharged from local inpatient units located closely to the local outpatient clinic.

The alliance between the therapist and the patient is widely described in the literature to be essential for a good effect of psychotherapy, ${ }^{32-38}$ and the importance of the socalled Critical Time Intervention for continuity of care is well documented. ${ }^{39}$ Continuous contact with an entrusted health professional may help in avoiding gaps in service delivery after discharge from psychiatric hospital. ${ }^{40-42}$ In our local institution-based system, the opportunity for a therapist to keep continuous contact with the patients over the transition from inpatient to outpatient care is better than in the centralized model, where inpatients may have to re establish such a contact following discharge from hospital. These differences between our models in the opportunity to develop and maintain these alliances may at least partly explain the results. Consequently, effectiveness of mental health systems may to an extent be affected by how well they facilitate continuous relationships between patients and therapists.

Although a relationship between service organization and patient outcome is difficult to document, research suggests that the concept of "systems integration" is vital for continuity of care. ${ }^{43-45}$ In a more extended system, autonomous units or providers may guard their organizational borders and struggle for control, which may contribute to a low level of service integration. ${ }^{46,47}$ The integration of services may be essential, especially for patients with serious conditions such as schizophrenia or major depression. These patients may experience a reduced level of functioning that makes it difficult for them to orientate and persist in complex environments. ${ }^{48}$

One consequence of poor integration of inpatient and outpatient care may be that the discharge of inpatients is not coordinated with local services. ${ }^{49,50}$ In the centralized model, coordination of inpatient and outpatient treatment is mainly due to collaborative efforts between the $\mathrm{CMH}$ and 
the DPC, and differences in clinical opinions, and judgments may halt outpatient care after discharge. Discussion and exchange of relevant clinical information are of importance for continuity of care. ${ }^{51}$ In a locally integrated model, this may certainly be easier as there will be regular formal and informal encounters between clinicians concerning individual patients. In many cases, the same clinicians will follow the same patients in inpatient care and outpatient care. Again, this may be a lot easier when clinicians are able to meet with the patients regularly during their treatment course as in the locally integrated model.

\section{Limitations of the study}

The study's design, which is close to natural experimental, is an important strength. It is also strengthened by the fact that the catchment areas are geographically delimitated, with no leakage to private or other providers of treatment and care. Moreover, the similarity of the basic sociodemographic conditions in the two areas increases their comparability.

Our sample of 690 inpatients may not be considered to be very large. Nevertheless, as we found significant effects, we are able to claim that the associations found between the study variables are likely to be quite strong. As this was a study of all inpatients in two service-areas in a given time period, we did not perform a power analysis. However, we believe that the relatively high number of patients included reduces the chances of any type II errors.

It is a limitation of the study that we have relatively few variables characterizing the patients. The statistical impact of system variables could be reduced if additional clinical and psychosocial variables were available and were included. However, in the multivariate analyses, we have used the intensity of treatment, by volume of both inpatient and outpatient treatment for individual patients, a point of relevance missing in most studies on the topic. ${ }^{17}$

Being restricted to use ordinary clinical data, the reliability and validity of the diagnostics may also be questioned. We lack information about the quality of care. However, both service models are in accordance with national guidelines for service delivery and have adopted current clinical standards.

The results could have been affected by patients who were hospitalized before the start of the period or not yet discharged by the end of the period. We have, to a certain extent, controlled for this issue by including duration of inpatient treatment as a covariate in the regression model and also by the relative length of the observational period over a series of years.
While we may not generalize our results to other systems, we believe the present study adds to the literature on contemporary European psychiatric services. The importance of such studies in a range of different areas for informed policy planning has previously been highlighted. ${ }^{17,44,52-54}$

\section{Conclusion}

Psychiatric centers with local inpatient units may positively affect continuity of care for patients with severe psychiatric disorders, probably because of a high functional integration of inpatient and outpatient care. Local institution-based systems may meet the needs of these patients better than systems based on cooperation between specialized teams at central institutions and local outpatient units. The study does not support the idea that highly integrated services reduces hospitalization rates or the utilization of other services.

\section{Acknowledgments}

The authors gratefully acknowledge the support of the participating institutions. The study was partly supported by a grant from the Norwegian Research Council. The funders had no role in study design, data collection and analysis, and decision to publish, or preparation of the paper.

\section{Disclosure}

The authors report no conflicts of interest in this work.

\section{References}

1. Thornicroft G, Tansella M. Components of a modern mental health service: a pragmatic balance of community and hospital care: overview of systematic evidence. Brit J Psychiatry. 2004;185:283-290.

2. Segal SP. Managing transitions and ensuring good care. Psychiatr Serv. 2004;55:1205.

3. Thornicroft G, Bebbington P. Deinstitutionalisation - from hospital closure to service development. Brit J Psychiatry. 1989;155: 739-753.

4. Eaton WW. Strategies of measurement and analysis. In: Knudsen HC, Thornicroft G, editors. Mental Health Service Evaluation. Cambridge: Cambridge University Press; 1996.

5. Adair CE, McDougall GM, Beckie A, et al. History and measurement of continuity of care in mental health services and evidence of its role in outcomes. Psychiatr Serv. 2003;54:1351-1356.

6. Bacharach L. Continuity of care for chronic mental patients: A conceptual analysis. Am J Psychiatry. 1981;138:1449-1456.

7. Christakis DA. Continuity of care: process or outcome? Ann Fam Med. 2003; 1:131-133.

8. Johnson S, Prosser D, Bindman J, Szmukler G. Continuity of care for the severely mentally ill: concepts and measures. Soc Psychiatry Psychiatr Epidemiol. 1997;32:137-142.

9. Stroul C, Friedman G. A System of Care for Severely Emotionally Disturbed Children and Youth. Washington, DC: National Institute of Mental Health, 1986.

10. Saarento O, Oiesvold T, Sytema S, et al. The Nordic Comparative Study on Sectorized Psychiatry: continuity of care related to characteristics of the psychiatric services and the patients. Soc Psychiatry Psychiatr Epidemiol. 1998;33:521-527. 
11. Sytema S, Burgess P. Continuity of care and readmission in two service systems: a comparative Victorian and Groningen case-register study. Acta Psychiatr Scand. 1999;100:212-219.

12. Bindman J, Johnson S, Szmukler G, et al. Continuity of care and clinical outcome: a prospective cohort study. Soc Psychiatry Psychiatr Epidemiol. 2000;35:242-247.

13. Adair CE, McDougall GM, Mitton CR, et al. Continuity of care and health outcomes among persons with severe mental illness. Psychiatr Serv. 2005;56:1061-1069.

14. Ravelli DP. Deinstitutionalisation of mental health care in The Netherlands: towards an integrative approach. Int J Integr Care. 2006;6:e04.

15. Alonso SuarezM, Bravo-Ortiz MF, Fernandez-LiriaA, Gonzalez-Juarez C. Effectiveness of continuity-of-care programs to reduce time in hospital in persons with schizophrenia. Epidemiol Psychiatr Sci. 2011;20:65-72.

16. Jarrett M, Thornicroft G, Forrester A, et al. Continuity of care for recently released prisoners with mental illness: a pilot randomised controlled trial testing the feasibility of a Critical Time Intervention. Epidemiol Psychiatr Sci. 2012;21:187-193.

17. Omer S, Priebe S, Giacco D. Continuity across inpatient and outpatient mental health care or specialisation of teams? A systematic review. Eur Psychiatry. 2015;30:258-270.

18. Myklebust LH, Sorgaard K, Bjorbekkmo S, Nymann A, Molvik S, Olstad R. Bed utilization in two differently organized community mental health services in Northern Norway: the VELO-project. Soc Psychiatry Psychiatr Epidemiol. 2009;44:550-557.

19. Myklebust LH, Olstad R, Bjorbekkmo S, Eisemann M, Wynn R, Sorgaard K. Impact on continuity of care of decentralized versus partly centralized mental health care in Northern Norway. Int J Integr Care. 2011;11:e142.

20. The Directorate for Health and Social Affairs. Distriktspsykiatriske sentra [District psychiatric centres]. Oslo: The Directorate for Health and Social Affairs; 2006. Norwegian.

21. The Directorate for Health and Social Affairs. Opptrappingsplanen for psykisk helse [The Plan on the escalation of psychiatric services]. Oslo: The Directorate for Health and Social Affairs; 1999. Norwegian.

22. Gebhardt RP, Schmidt-Michel PO. Eine psychiatrische Akut-Station zieht in die Gemeinde [An acute psychiatric ward moves into the community. An empirical test of the satellite model]. Nervenarzt. 2002;73:1088-1093. German.

23. Wynn R. Coercion in psychiatric care: clinical, legal, and ethical controversies. Int J Psychiatry Clin Pract. 2006;10:247-251.

24. Wynn R, Myklebust LH, Bratlid T. Psychologists and coercion: decisions regarding involuntary psychiatric admission and treatment in a group of Norwegian psychologists. Nord J Psychiatry. 2007;61:433-437.

25. Myklebust LH, Sorgaard K, Rotvold K, Wynn R. Factors of importance to involuntary admission. Nord J Psychiatry. 2012;66:178-182.

26. Myklebust LH, Sorgaard K, Wynn R. Local psychiatric beds appear to decrease the use of involuntary admission: a case-registry study. $B M C$ Health Serv Res. 2014;14:64.

27. Norwegian Mapping Authority. Norwegian Maps. Available from: http://www.norgeskart.no. Accessed September 1, 2015.

28. Wideroes Flyselskap A/S (Airline Company). Available from: http:// www.wideroe.no/en. Accessed: September 1, 2015.

29. Statistics Norway. Available at: https://www.ssb.no/en. Accessed: September 1, 2015.

30. The Norwegian Labour and Welfare Administration. Uføretrygd [disability pension]. Available from: http://www.nav.no. Accessed September 1, 2015. Norwegian.

31. Cohen JW. Statistical Power Analysis for the Behavioural Sciences. 2nd ed. Hillsdale, NJ: Lawrence Earlbaum Associates; 1988.

32. Littauer H, Sexton H, Wynn R. Qualities clients wish for in their therapists. Scand J Caring Sci. 2005;19:28-31.
33. Wynn R. Empathy in general practice consultations: a qualitative analysis. Epidemiol Psichiatr Soc. 2005;14:163-169.

34. Hoxmark E, Wynn R. Health providers' descriptions of the significance of the therapeutic relationship in treatment of patients with dual diagnoses. J Addict Nurs. 2010;21:187-193.

35. Green CA, Polen MR, Janoff SL, et al. Understanding how clientpatient relationships and relational continuity of care affect recovery from seriq mental illness: STARS study results. Psychiatr Rehab J. 2008;32:9-22.

36. Barnicot K, Katsakou, Bhatti CN, Savill M, Fearns N, Priebe S. Factors predicting the outcome of psychotherapy for borderline personality disorder: a systematic review. Clin Psychol Rev. 2012;32:400-412.

37. Degnan A, Seymour-Hyde A, Harris A, Berry K. The role of therapist attachment in alliance and outcome: A systematic literature review. Clin Psychol Psychother. Epub 2014 Dec 2.

38. Bergvik S, Sørlie T, Wynn R. Coronary patients who returned to work had stronger internal locus of control beliefs than those who did not return to work. Br J Health Psychol. 2012;17:596-608.

39. Tomita A, Herman DB. The role of critical time intervention on the experience of continuity of care among persons with severe mental illness after hospital discharge. J Nerv Ment Dis. 2015;203:65-70.

40. Boyer CA, McAlpine DD, Pottick KJ, Olfson M. Identifying risk factors and key strategies in linkage to outpatient psychiatric care. Am J Psychiatry. 2000;157:1592-1598.

41. Compton MT, Rudisch BE, Craw J, Thompson T, Owens DA. Predictors of missed first appointments at community mental health centers after psychiatric hospitalization. Psychiatr Serv. 2006;57:531-537.

42. Forchuk C, Reynolds W, Sharkey S, Martin ML, Jensen E. Transitional discharge based on therapeutic relationships: state of the art. Arch Psychiatr Nurs. 2007;21:80-86.

43. Bindman $\mathrm{J}$, Johnson $\mathrm{S}$, Wright $\mathrm{S}$, et al. Integration between primary and secondary services in the care of the severely mentally ill: patients' and general practitioners' views. Br J Psychiatry 1997;171:169-174.

44. Fleury MJ, Imboua A, Aube D, Farand L. Collaboration between general practitioners (GPs) and mental healthcare professionals within the context of reforms in Quebec. Ment Health Fam Med. 2012;9:77-90.

45. Durbin J, Goering P, Streiner DL, Pink G. Does systems integration affect continuity of mental health care? Adm Policy Ment Health. 2006;33:705-717.

46. Hoge MA, Howenstine RA. Organizational development strategies for integrating mental health services. Community Ment Health J. 1997;33: $175-187$.

47. Greenberg GA, Rosenheck RA. Continuity of care and clinical outcomes in a national health system. Psychiatr Serv. 2005;56:427-433.

48. Sørgaard KW, Nivison M, Hansen V, Øiesvold T. Acknowledging illness and treatment needs in first-time admitted psychiatric patients. Eur Psychiatry. 2011;26:446-451.

49. Bjorbekkmo S, Myklebust LH, Olstad R, Molvik S, Nymann A, Sorgaard K. Decentralization matters - Differently organized mental health services relationship to staff competence and treatment practice: the VELO study. Int J Ment Health Syst. 2009;3:9.

50. Thornicroft G, Tansella M. The Mental Health Matrix: A Manual to Improve Services. Cambridge, UK: Cambridge University Press, 1999.

51. Farrell SP, Blank M, Koch JR, Munjas B, Clement DG. Predicting whether patients receive continuity of care after discharge from state hospitals: policy implications. Arch Psychiatr Nurs. 1999;13:279-285.

52. Fleury MJ. Quebec mental health services networks: models and implementation. Int J Integr Care. 2005;5:e07.

53. Verdoux H. The current state of adult mental health care in France. Eur Arch Psychiatry Clin Neurosci. 2007;257:64-70.

54. Salvador-Carulla L, Saldivia S, Martinez-Leal R, et al. Meso-level comparison of mental health service availability and use in Chile and Spain. Psychiatr Serv. 2008;59:421-428. 
Psychology Research and Behavior Management

Dovepress

\section{Publish your work in this journal}

Psychology Research and Behavior Management is an international, peerreviewed, open access journal focusing on the science of psychology and its application in behavior management to develop improved outcomes in the clinical, educational, sports and business arenas. Specific topics covered include: Neuroscience, memory \& decision making; Behavior modification \& management; Clinical applications; Business \& sports performance management; Social and developmental studies; Animal studies. The manuscript management system is completely online and includes a quick and fair peer-review system. Visit http://www.dovepress. com/testimonials.php to read real quotes from published authors.

Submit your manuscript here: http://www.dovepress.com/psychology-research-and-behavior-management-journal 